Ouachita Baptist University

Scholarly Commons @ Ouachita

Articles

Faculty Publications

2005

\title{
Gauss, Johann Carl Friedrich
}

Randall D. Wight

Ouachita Baptist University, wight@obu.edu

Philip A. Gable

Follow this and additional works at: https://scholarlycommons.obu.edu/articles

\section{Recommended Citation}

Wight, R. D. \& Gable, P. A. (2005). Gauss, Johann Carl Friedrich. Encyclopedia of Statistics in Behavioral Science (Vol. 2, pp. 694-696). London: Wiley.

This Article is brought to you for free and open access by the Faculty Publications at Scholarly Commons @ Ouachita. It has been accepted for inclusion in Articles by an authorized administrator of Scholarly Commons @ Ouachita. For more information, please contact mortensona@obu.edu. 


\title{
Gauss, Johann Carl Friedrich
}

\author{
Randall D. Wight and Philip A. Gable \\ Volume 2, pp. 694-696 \\ in \\ Encyclopedia of Statistics in Behavioral Science \\ ISBN-13: 978-0-470-86080-9 \\ ISBN-10: 0-470-86080-4 \\ Editors
}

Brian S. Everitt \& David C. Howell

(C) John Wiley \& Sons, Ltd, Chichester, 2005 


\section{Gauss, Johann Carl Friedrich}

Born: April 30, 1777, in Brunswick, Germany. Died: February 23, 1855, in Göttingen, Germany.

Born to humble means in the Duchy of Brunswick (now in Germany), Carl Friedrich Gauss's contributions spanned a lifetime and earned the epithet 'Prince of Mathematicians'. As a mathematical scientist, often ranked with Archimedes and Newton, Gauss is among the elite of any era. In 1784, he entered a Brunswick gymnasium that recognized his talent. By age 14, the Duke of Brunswick granted Gauss a stipend and he entered the Collegium Carolinium, where he studied modern languages as well as the works of Newton, Euler, and Lagrange. In 1795, he entered the University of Göttingen. Shortly thereafter, entries in Gauss's personal notebooks contained groundbreaking insights into number theory. Within a year, Gauss also constructed a 17-sided regular polygon using only ruler and compass - the first so constructed since antiquity. Gauss returned to Brunswick in 1798 and entered the University of Helmstedt, from which he earned a doctorate the following year. The dissertation, published in 1801, contains Gauss's first proof of the fundamental theorem of algebra. Also in 1801, without publishing his method, Gauss correctly predicted the location of the first-known, recently discovered asteroid, Ceres. His brilliance emerged at an early age.

Gauss's contributions to statistics revolve around the conceptual convergence known as the GaussLaplace synthesis. Occurring in the years following 1809 , this foundational merger advanced effective methods for combining data with the ability to quantify error. Gauss's role in this synthesis centers in his account of least squares, his use of the normal curve, and the influence this work had on PierreSimon Laplace.

During the mid-seventeenth century, astronomers wanted to know how best to combine a number of independent but varying observations of the same phenomenon. Among the most promising procedures was the method of least squares (see Least Squares Estimation), which argues that the minimal distance to the true value of a distribution of observations is the sum of squared deviations from the mean. In
1807, Gauss became director of the University of Göttingen's observatory. Despite early applications of least squares insights, Gauss failed to publish an account until 1809, and even then only in the last chapter of a major contribution to celestial mechanics [2]. A priority dispute arose with Adrien Marie Legendre, who first published a least squares discussion in 1805 .

However, the respect afforded Gauss always gave pause to quick dismissals of his priority claims. Even if least squares publication priority belongs to Legendre, Gauss offered a sophisticated elaboration of the method. In addition to developing least squares, the 1809 publication contained another seminal contribution to statistics, that is, use of the normal distribution to describe measurement error. Here, Gauss employed Laplace's probability curve for sums and means to describe the measurement of random deviations around the true measurement of an astronomical event. Because of this insight, by the end of the nineteenth century, what we know today as the normal distribution came to be known as the Gaussian distribution. Although Gauss was not the first to describe the normal curve, he was the first to use it to assign precise probabilities to errors. In honor of this insight, the 10 Deutschmark would one day bear both an image of Gauss and the normal curve's geometric and formulaic expression.

The 1809 Gaussian insights proved a conceptual catalyst. In 1810, Laplace presented what we know today as the central limit theorem: the distribution of any sufficiently sampled variable can be expressed as the sum of small independent observations or variables approximating a normal curve. When Laplace read Gauss's 1809 book later that year, he recognized the connection between his theorem, the normal distribution, and least squares estimates. If errors are aggregates, then errors should distribute along the normal curve with least squares providing the smallest expected error estimate. The coming years were a conceptual watershed as additional work by Gauss, Laplace, and others converged to produce the Gauss-Laplace synthesis. As Youden ([5], p. 55) later observed "The normal law of error stands out... as one of the broadest generalizations of natural philosophy... It is an indispensable tool for the analysis and the interpretation of the basic data obtained by observation and experiment". Following 1809 , these insights spread from astronomy to physics and the military. Absorption into the social sciences 
took more time. By the time the use of least squares flowered in the social sciences, Galton, Pearson, and Yule had uniquely transformed the procedure into the techniques of regression (see Multiple Linear Regression) and analysis of variance [3, 4].

In addition to the Gauss-Laplace synthesis, Gauss's more general contributions include the fundamental theorems of arithmetic and algebra and development of the algebra of congruence. He published important work on actuarial science, celestial mechanics, differential geometry, geodesy, magnetism, number theory, and optics. He invented a heliotrope, magnetometer, photometer, and telegraph. Sub rosa, he was among the first to investigate non-Euclidean geometry and, in 1851, approved Riemann's doctoral thesis. Indeed a titan of science [1], Gauss was extraordinarily productive throughout his life, although his personal life was not without turmoil. After developing heart disease, Gauss died in his sleep in late February, 1855.

\section{References}

[1] Dunnington, G.W. (1955). Carl Friedrich Gauss, Titan of Science: A Study of his Life and Work, Exposition Press, New York.

[2] Gauss, C.F. (1809/1857/2004). Theoria Motus Corporum Coelestium in Sectionibus Conicis Solum Ambientium, [Theory of the motion of the heavenly bodies moving about the sun in conic sections] Translated by, C.H. Davis, ed., Dover Publications, Mineola, (Original work published 1809; original translation published 1857).

[3] Stigler, S.M. (1986). The Measurement of Uncertainty Before 1900, Harvard University Press, Cambridge.

[4] Stigler, S.M. (1999). Statistics on the Table: The History of Statistical Concepts and Methods, Harvard University Press, Cambridge.

[5] Youden, W.J. (1994). Experimentation and Measurement, U.S. Department of Commerce, Washington.

Randall D. Wight AND PhILIP A. GABLE 